\title{
Keanekaragaman Tumbuhan Pakan Orangutan Sumatera (Pongo abelii Lesson 1827) Berdasarkan Strata Pertumbuhan Tegakan di Stasiun Penelitian Soraya Kawasan Ekosistem Leuser (Diversity of Sumatran Orangutan Feed Plants (Pongo abelii Lesson 1827) Based on Standing Growth Strata at the Soraya Research Station in the Leuser Ecosystem)
}

\author{
Intan Regina ${ }^{1}$, Erdiansyah Rahmi ${ }^{2}$, Iqbar $^{3 *}$ \\ ${ }^{1}$ Program Studi Kehutanan PSDKU Unsyiah Gayo Lues, Universitas Syiah Kuala \\ ${ }^{2}$ Fakultas Kedoktran Hewan, Universitas Syiah Kuala \\ ${ }^{3}$ Program Studi Kehutanan, Fakultas Pertanian, Universitas Syiah Kuala \\ *Corresponding author: iqbar@unsyiah.ac.id
}

\begin{abstract}
Abstrak. Soraya adalah salah satu stasiun penelitian yang dikelola oleh Forum Konservasi Leuser (FKL) yang berada dalam Kawasan Ekosistem Leuser (KEL). Penelitian ini bertujuan untuk mengetahui Indeks Nilai Penting (INP) tumbuhan pakan orangutan sumatera berdasarkan strata pertumbuhan tegakan hutan dan Indeks keanekaragaman tumbuhan pakan orangutan sumatera berdasarkan strata pertumbuhan tegakan hutan. Metode yang digunakan dalam penelitian ini yaitu garis berpetak dibuat memanjang mengikuti jalur yang sudah ada dengan panjang 1000 meter dengan jarak antar petak contoh $50 \mathrm{~m}$. Petak contoh dibuat sesuai strata pertumbuhan tegakan $2 \mathrm{~m} \times 2 \mathrm{~m}$ untuk semai, $5 \mathrm{~m} \times 5 \mathrm{~m}$ untuk pancang, $10 \mathrm{~m} \times 10 \mathrm{~m}$ untuk tiang dan $20 \mathrm{~m} \times$ $20 \mathrm{~m}$ untuk pohon dengan jumlah total masing-masing sebanyak 14 petak contoh. Indeks Nilai Penting (INP) tertinggi tumbuhan pakan orangutan sumatera berdasarkan strata semai yaitu Artocarpus integer (47,7 \%), strata pancang yaitu Cyathocalix sumatranus (32,9) Streblus elongatus (46,5\%) dan strata pohon yaitu Dipterocarpus grandiflorus $(57,7 \%)$. Indeks keanekaragaman tumbuhan pakan orangutan sumatera pada strata semai 1,86 (sedang), strata pancang 2,38 (sedang), strata tiang 3,35 (tinggi), strata pohon 2,62 (sedang).
\end{abstract}

Kata kunci : Orangutan sumatera, keanekaragaman tumbuhan pakan dan Stasiun Penelitian Soraya

\begin{abstract}
Soraya is one of the research stations managed by the Leuser Conservation Forum (FKL) in the Leuser Ecosystem Area (KEL). This study aims to determine the Important Value Index (IVI) of forage plants to feed Sumatran orangutan based on growth strata of forest stands and the diversity index of plant growth of Sumatran orangutan for feed based on strata growth of forest stands. The method used in this study is that the plotted line is made to follow the existing path with a length of 1000 meters with a spacing between $50 \mathrm{~m}$ samples according to the growth stratum $2 \mathrm{~m} \times 2 \mathrm{~m}$ for seedlings, $5 \mathrm{~m} \times 5 \mathrm{~m}$ for saplings, $10 \mathrm{mx} 10 \mathrm{~m}$ for poles and $20 \mathrm{~m}$ x $20 \mathrm{~m}$ for tree of 14 sample plots. The highest Importance Value Index (IVI) of Sumatran orangutan forage plants is based on the seedling strata, namely Artocarpus integer (47,7\%), sapling strata, Cyathocalix sumatranus $(32,9)$ Streblus elongatus $(46,5 \%)$ and tree strata namely Dipterocarpus grandiflorus $(57,7 \%)$. Sumatran orangutan food plant diversity index at 1,86 (medium) seedling strata, 2,38 (medium) saplings, 3,35 pole pole strata (high), 2,62 tree strata (medium).
\end{abstract}

Keywords: Sumatran Orangutan, diversity of forage food plants and Soraya Research Station

\section{PENDAHULUAN}

Orangutan sumatera (Pongo abelii) adalah salah satu spesies orangutan di Indonesia dan hanya dapat ditemukan di Pulau Sumatera. Orangutan sumatera saat ini termasuk kategori satwa yang digolongkan kritis (Critically Endangered) akibat perusakan hutan oleh manusia dan perburuan liar (IUCN, 2014). Orangutan sumatera hidup secara semi soliter dan arboreal pada ekosistem hutan, terutama pada hutan yang memiliki pohon yang 
menghasilkan buah sebagai sumber pakan utamanya. Oleh karena itu distribusi, jumlah dan kualitas makanannya menurut waktu dan tempat tertentu merupakan faktor penentu utama perilaku pergerakan, kepadatan populasi yang akhirnya menentukan organisasi sosialnya (Kuswanda, 2014).

Habitat yang cocok untuk melestarikan orangutan sumatera yaitu daerah yang mempunyai hutan hujan tropis dataran rendah dan hutan rawa gambut yang banyak tersedia pakan untuk orangutan sumatera. Ketersediaan pakan berdasarkan strata pertumbuhan tegakan akan tetap terjaga apabila primata pemakan buah besar tidak dikeluarkan dari hutan tropis akibat perburuan maka penyebaran spesies pohon berbiji besar akan tetap ada dan berkembang. Selain itu, orangutan juga memainkan peran aktif dalam perkecambahan biji untuk spesies tertentu (Ancrenaz et al. 2006).

Soraya adalah salah satu stasiun penelitian yang dikelola oleh Forum Konservasi Leuser (FKL) yang berada dalam kawasan ekosistem Leuser. Secara adminitratif stasiun penelitian Soraya berada di Kecamatan Sultan Daulat, Kota Subulussalam, Provinsi Aceh. Topografi stasiun penelitian Soraya berada di dataran rendah yaitu 75-350 m dpl sehingga menjadikan kawasan ini kaya akan biodiversitas flora. Status Stasiun Penelitian Soraya adalah kawasan konservasi yang termasuk ke dalam Kawasan Ekosistem Leuser (KEL) dengan luas areal sekitar 6000 ha yang memiliki keanekaragaman flora dan fauna. Stasiun penelitian Soraya dibangun untuk kegiatan penelitian serta untuk melindungi satwa dan memperkuat sistem pengamanan kawasan ekosistem leuser dari ancaman pembukaan kawasan hutan. Soraya berfungsi sebagai pusat penelitian keanekaragaman sehingga diperlukan penelitian tentang keanekaragaman tumbuhan pakan orangutan sumatera berdasarkan strata pertumbuhan tegakan di Stasiun Penelitian Soraya Kawasan Ekosistem Leuser

\section{METODE PENELITIAN}

\section{Lokasi}

Lokasi penelitian dilakukan di Stasiun Penelitian Soraya Kawasan Ekosistem Leuser yang berada di Kecamatan Sultan Daulat, Kota Subulussalam, Provinsi Aceh.

\section{Alat dan Bahan}

Alat yang digunakan dalam penelitian ini yaitu kamera, sasak (herbarium press), alat tulis, thally sheet, pita meter, tali rafia dan pancang. Bahan yang digunakan yaitu daftar tumbuhan pakan orangutan sumatera yang sudah pernah ada yaitu daftar tumbuhan pakan orang utan di Ketambe, koran bekas, dan alkohol $70 \%$.

\section{Cara Kerja}

Dalam penelitian ini komunitas yang diamati yaitu hutan yang terdapat di Stasiun Penelitian Soraya dengan menggunakan petak ukur yang di dalamnya terdapat strata tegakan. Data yang akan diinventarisari yaitu tegakan yang merupakan tumbuhan pakan orangutan sumatera berdasarkan strata semai, pancang, tiang dan pohon. Inventarisasi ini menggunakan metode garis berpetak. Garis berpetak dibuat memanjang mengikuti jalur 
yang sudah ada dengan panjang $1000 \mathrm{~m}$ (Gambar 1), petak contoh garis berpetak dibuat dengan ukuran sesuai strata pertumbuhan tegakan yaitu:

- Petak ukur $2 \mathrm{~m}$ x $2 \mathrm{~m}$ untuk tingkat semai, yaitu permudaan mulai dari kecambah sampai tinggi $\leq 1,5 \mathrm{~m}$.

- Petak ukur $5 \mathrm{~m}$ x $5 \mathrm{~m}$ untuk tingkat pancang dengan diameter $<10 \mathrm{~cm}$.

- Petak ukur $10 \mathrm{~m} \times 10 \mathrm{~m}$ untuk tingkat tiang dengan diameter setinggi dada $(1,3 \mathrm{~m})$ antara $\geq 10$ sampai $<20 \mathrm{~cm}$.

- Petak ukur 20m x 20m untuk tingkat pohon dengan diameter setinggi dada $(1,3 \mathrm{~m}) \geq 20 \mathrm{~cm}$, bila pohon berbanir diameter diukur $20 \mathrm{~cm}$ di atas banir.

Jarak antar petak contoh dalam satu transek adalah 50 m dengan 1 transek dan 14 petak contoh yang akan dilakukan inventarisasi tegakan tumbuhan pakan orangutan sumatera. Penempatan plot dilakukan dengan pemilihan lokasi dengan kondisi vegetasi yang baik dan merupakan jalur daerah jelajah orangutan sumatera. Tumbuhan yang mampu dikenali langsung dicatat ke dalam lembar data sedangkan yang belum dikenali dilakukan pembuatan herbarium untuk dilakukan identifikasi lebih lanjut.

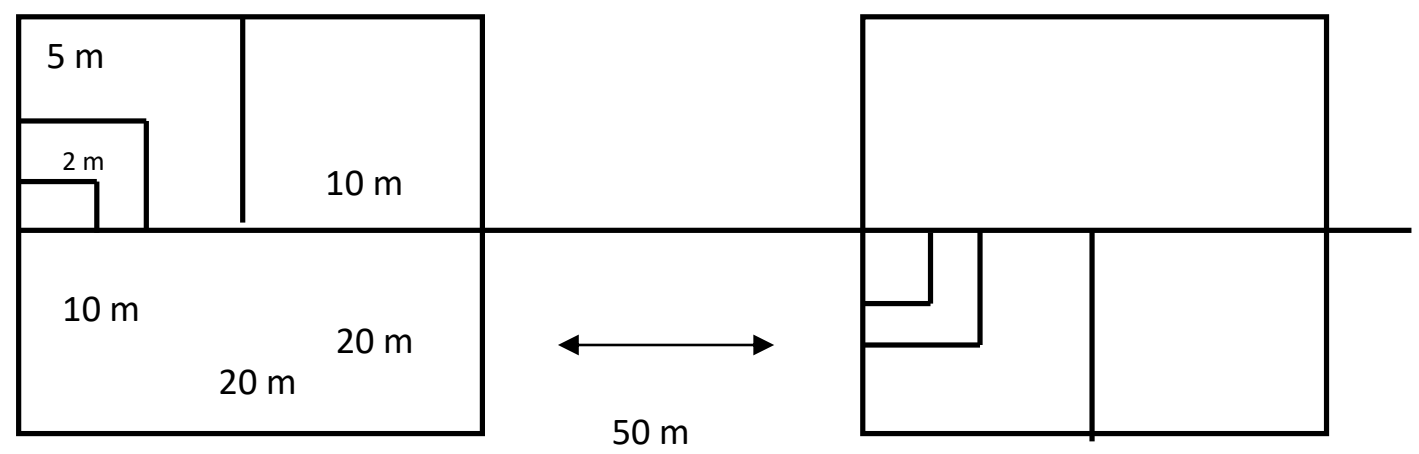

Gambar 1. Desain petak-petak contoh di lapangan dengan metode garis berpetak (Kusmana, 1997 dalam Fahrul, 2007)

\section{Parameter dan Analisis Data}

Parameter penelitian adalah kerapatan, kerapatan relatif, dominansi, dominansi relatif, frekuensi dan frekuensi relatif serta Indeks Nilai Penting (INP) dan Indeks Keanekaragaman menggunakan rumus Shannon-Wiener Index (Magurran, 1998). Analisis data dilakukan dengan menggunakan rumus yang dikemukan oleh Fachrul (2007) sebagai berikut:

1. Strata semai dan pancang dengan menggunakan rumus:

a. Kerapatan

b. Kerapatan Relatif

$$
\text { Kerapatan }(\mathrm{K})=\frac{\text { Jumlah individu suatu jenis }}{\text { Luas seluruh petak contoh }}
$$

$$
\text { Kerapatan Relatif }(\mathrm{KR})=\frac{\text { Kerapatan suatu jenis }}{\text { Kerapatan seluruh jenis }} \times 100 \%
$$

c. Frekuensi 
d. Frekuensi Relatif

$$
\text { Frekuensi }(\mathrm{F}) \quad=\frac{\text { Jumlah petak terisi suatu jenis }}{\text { Jumlah seluruh petak }}
$$

$$
\text { Frekuensi Relatif }(F R)=\frac{\text { Frekuensi suatu jenis }}{\text { Frekuensi semua jenis }} \times 100 \%
$$

e. Indeks Nilai Penting (INP) $=\mathrm{KR}+\mathrm{FR}$

f. Indeks Keanekaragaman $\left(\mathrm{H}^{\prime}\right)=-\sum \mathrm{ni} / \mathrm{N} \ln \mathrm{ni} / \mathrm{N}$

2. Strata pohon dan tiang dengan menggunakan rumus:

a. Kerapatan

$$
\text { Kerapatan }(\mathrm{K}) \quad=\frac{\text { Jumlah individu suatu jenis }}{\text { Luas seluruh petak contoh }}
$$

b. Kerapatan Relatif

c. Frekuensi

$$
\text { Kerapatan Relatif }(K R)=\frac{\text { Kerapatan suatu jenis }}{\text { Kerapatan seluruh jenis }} \times 100 \%
$$

$$
\text { Frekuensi }(\mathrm{F}) \quad=\frac{\text { Jumlah petak terisi suatu jenis }}{\text { Jumlah seluruh petak }}
$$

d. Frekuensi Relatif

$$
\text { Frekuensi Relatif }(\mathrm{FR})=\frac{\text { Frekuensi suatu jenis }}{\text { Frekuensi semua jenis }} \times 100 \%
$$

e. Dominansi

$$
\text { Dominansi (D) } \quad=\frac{\text { Luas bidang dasar suatu jenis }}{\text { Luas seluruh petak contoh }}
$$

f. Dominansi Relatif

$$
\text { Lbds } \quad=(\mathrm{d} / 2)^{2} \times 3,14
$$

$$
\text { Dominansi Relatif }(D R)=\frac{\text { Domiansi suatu jenis }}{\text { Jumlah dominansi seluruh jenis }} \times 100 \%
$$

g. Indeks Nilai Penting (INP) $\quad=\mathrm{KR}+\mathrm{FR}+\mathrm{DR}$

h. Indeks Keanekaragaman $\left(\mathrm{H}^{\prime}\right)=-\sum \mathrm{ni} / \mathrm{N} \ln \mathrm{ni} / \mathrm{N}$

\section{HASIL DAN PEMBAHASAN}

\section{Indeks Nilai Penting (INP) Tumbuhan Pakan Orangutan Sumatera}

Indeks Nilai Penting (INP) tumbuhan pakan orangutan sumatera dihitung berdasarkan strata pertumbuhan tegakan. Nilai yang dihitung di lapangan adalah nilai 
Kerapatan Mutlak, Frekuensi Mutlak dan Dominansi Mutlak. Nilai ini selanjutnya digunakan untuk mendapatkan nilai Kerapatan Relatif (KR), Frekuensi Relatif (FR) dan Dominansi Relatif (DR). Penjumlahan ketiga nilai tersebut dapat diperoleh Indeks Nilai Penting (INP). INP setiap strata pertumbuhan tumbuhan pakan orang utan sumatatera di Stasiun Penelitian Soraya KEL ditampilan pada tabel 1 hingga tabel 3.

Tabel 1. Indeks Nilai Penting (INP) Tumbuhan Pakan Orangutan sumatera Strata Pohon

\begin{tabular}{|c|c|c|c|c|c|}
\hline No & Jenis & $\begin{array}{l}\text { KR } \\
(\%) \\
\end{array}$ & $\begin{array}{l}\text { FR } \\
(\%)\end{array}$ & $\begin{array}{l}\text { DR } \\
(\%)\end{array}$ & $\begin{array}{l}\text { INP } \\
(\%)\end{array}$ \\
\hline 1 & Asam Terong (Canarium pilosum Benn.) & 1,08 & 1,42 & 0,76 & 3,28 \\
\hline 2 & Bau Langit (Cyathocalix sumatranus) & 4,34 & 4,28 & 3,35 & 11,9 \\
\hline 3 & Bintangur Inai (Pternandra caerukescens Jack.) & 2,17 & 1,42 & 1,70 & 5,31 \\
\hline 4 & Cempedak (Artocarpus integer) & 2,17 & 2,85 & 1,94 & 6,98 \\
\hline 5 & Damli (Streblus elongatus) & 17,3 & 14,2 & 15,6 & 47,3 \\
\hline 6 & Jambu Gunung (Psidium sp1.) & 2,17 & 2,85 & 1,70 & 6,73 \\
\hline 7 & Jambu Kepal(Psidium sp2.) & 5,43 & 4,28 & 4,51 & 14,2 \\
\hline 8 & Kandis (Garcinia sp.) & 4,34 & 4,28 & 3,85 & 12,4 \\
\hline 9 & Kayu Karet (Elateriospermum tapos) & 8,69 & 5,71 & 7,81 & 22,2 \\
\hline 10 & Keruing gajah (Dipterocarpus grandiflorus) & 16,3 & 18,5 & 22,8 & 57,7 \\
\hline 11 & Pakam (Pometia pinnata) & 1,08 & 1,42 & 0,83 & 3,34 \\
\hline 12 & Pepening (Shorea multiflora) & 8,69 & 8,57 & 9,17 & 26,4 \\
\hline 13 & Rambutan Biawak (Nephelium rambutan-ake) & 2,17 & 2,85 & 2,71 & 7,74 \\
\hline 14 & Rumpi Rawan (Mallotus sphaerocarpus) & 2,17 & 2,85 & 1,60 & 6,63 \\
\hline 15 & Setur Padi (Aglaia korthalsii) & 2,17 & 2,85 & 2,37 & 7,40 \\
\hline 16 & Tampu Tapak Gajah (Macaranga tribolata) & 7,60 & 5,71 & 7,11 & 20,4 \\
\hline 17 & Tampu Licin (Macaranga diapenhoratil) & 4,34 & 4,28 & 3,99 & 12,6 \\
\hline 18 & Terap (Artocarpus elasticus) & 5,43 & 8,57 & 5,26 & 19,2 \\
\hline \multirow[t]{2}{*}{19} & Ubar Kacang (Horsfieldia crassifolia Hook.f.) & 2,17 & 2,85 & 2,77 & 7,81 \\
\hline & Jumlah & 100 & 100 & 100 & 300 \\
\hline
\end{tabular}

Tumbuhan pakan orang utan sumatera strata pohon di Stasiun Penelitian Soraya ditemukan paling tidak ada 19 jenis. Tumbuhan pakan strata ini yang lebih dominan dari tumbuhan pakan lainnya adalah keruing gajah (Dipterocarpus grandiflorus) dengan nilai $57,7 \%$ dan jenis damli (Streblus elongatus) dengan nilai 47,3\%. Jenis tumbuhan pakan ini mendominasi pada strata pohon yang terdapat dalam 14 petak contoh pengamatan. Dalam penelitian Muhammad (2019) di kawasan hutan Area Penggunaan Lain (APL) Hutan Batang Toru Sumatera Utara terdapat 2 jenis tumbuhan pakan yang dimakan orangutan pada strata pohon yaitu beringin (Ficus benjamina) dengan nilai 38,6\% dan durian (Durio zibethinus) dengan nilai $107,3 \%$. Kedua jenis ini bukan merupakan makanan orang utan sumatera di Stasiun Soraya karena pada areal penelitian yang diteliti tidak ditemukan adanya pohon beringin dan pohon durian.

Tabel 2. Indeks Nilai Penting (INP) Tumbuhan Pakan Orangutan sumatera Strata Tiang

\begin{tabular}{llcccc}
\hline No & \multicolumn{1}{c}{ Jenis } & KR & FR & DR & INP \\
& & $(\boldsymbol{\%})$ & $(\boldsymbol{\%})$ & $\begin{array}{l}(\boldsymbol{\%}) \\
(\boldsymbol{\%})\end{array}$ \\
\hline 1 & Asam Limau Hantu (CitrusBenn.) & 5,50 & 6,66 & 6,98 & 19,1 \\
2 & Bau Langit (Cyathocalix sumatranus) & 0,91 & 1,33 & 1,29 & 3,54
\end{tabular}




\begin{tabular}{|c|c|c|c|c|c|}
\hline \multirow[b]{2}{*}{ No } & \multicolumn{5}{|c|}{$\begin{array}{r}\text { JURNAL ILMIAH MAHASISWA PERTANIAN } \\
\text { E-ISSN: 2614-6053 P-ISSN: 2615-2878 } \\
\text { Volume 5, Nomor 3, Agustus } 2020 \\
w w w . j i m . u n s y i a h . a c . i d / J F P\end{array}$} \\
\hline & Jenis & $\begin{array}{l}\text { KR } \\
(\%)\end{array}$ & $\begin{array}{l}\text { FR } \\
(\%)\end{array}$ & $\begin{array}{l}\text { DR } \\
(\%)\end{array}$ & $\begin{array}{l}\text { INP } \\
(\%)\end{array}$ \\
\hline 3 & Bintangur Inai (Pternandra caerukescens Jack.) & 6,42 & 6,66 & 7,78 & 20,8 \\
\hline 4 & Berhul (Mangifera foetida) & 0,91 & 1,33 & 1,70 & 3,95 \\
\hline 5 & Cempedak (Artocarpus integer) & 3,66 & 4 & 5,27 & 12,9 \\
\hline 6 & Damli (Streblus elongatus) & 22,0 & 16 & 8,54 & 46,5 \\
\hline 7 & Jambu Gunung (Psidium sp1.) & 2,75 & 4 & 4,28 & 11,0 \\
\hline 8 & Jambu Kepal (Psidium sp2.) & 0,91 & 1,33 & 1,60 & 3,85 \\
\hline 9 & Kandis (Garcinia sp.) & 2,75 & 4 & 3,84 & 10,5 \\
\hline 10 & Kayu Arang (Diospyros sumatrana) & 0,91 & 1,33 & 1,18 & 3,43 \\
\hline 11 & Kayu Karet (Elateriospermumtapos) & 11,9 & 6,66 & 8,26 & 26,8 \\
\hline 12 & Keruing gajah (Dipterocarpus grandiflorus) & 13,7 & 13,3 & 9,24 & 36,3 \\
\hline 13 & Mangga Rusa (Mangifera indica) & 1,83 & 2,66 & 2,74 & 7,24 \\
\hline 14 & Manggis (Garcinia mangostana) & 0,91 & 1,33 & 1,54 & 3,79 \\
\hline 15 & Pakam (Pometia pinnata) & 1,83 & 2,66 & 2,86 & 7,36 \\
\hline 16 & Pepening (Shorea multiflora) & 8,25 & 9,33 & 8,98 & 26,5 \\
\hline 17 & Rumpi Rawan (Mallotus sphaerocarpus) & 1,83 & 2,66 & 3,44 & 7,94 \\
\hline 18 & Setur Padi (Aglaia korthalsii) & 1,83 & 4 & 3,37 & 9,20 \\
\hline 19 & Tampu Tapak Gajah (Macaranga tribolata) & 3,66 & 4 & 5,95 & 13,6 \\
\hline 20 & Tampang rawan (Blumeodendron tokbran) & 0,91 & 1,33 & 1,59 & 3,84 \\
\hline 21 & Terap (Artocarpus elasticus) & 6,42 & 5,33 & 9,46 & 21,2 \\
\hline & Jumlah & 100 & $\mathbf{1 0 0}$ & 100 & 300 \\
\hline
\end{tabular}

Pada strata pertumbuhan tiang juga terdapat 2 jenis dari 21 jenis tumbuhan pakan orangutan sumatera yang memiliki indeks nilai penting yang tinggi yaitu jenis tumbuhan pakan damli (Streblus elongatus) dengan nilai 46,5\% dan jenis keruing gajah (Dipterocarpus grandiflorus) dengan nilai 36,3\%. Jenis tumbuhan pakan ini selain mendominasi pada strata pohon juga mendominasi pada strata tiang yang terdapat dalam 14 petak contoh pengamatan. Dalam penelitian Muhammad(2019) tidak ditemukannya tumbuhan pakan orangutan pada strata tiang, sehingga ketersediaan pakan sangat sedikit. Pada Stasiun Penelitian Soraya ditemukan jenis pakan strata tiang dengan nilai INP yang tinggi sehingga ketersediaan pakan orangutan pada strata tiang sangat cukup karena Stasiun Penelitian Soraya bukan hutan klimaks, dimana hutan Soraya sudah pernah mengalami gangguan akibat ulah manusia. Kondisi ini memberi kesempatan terhadap tumbuhan untuk beregenerasi. Oleh karena itu ketersediaan pakan orang utan sumatera juga dapat terpenuhi dengan terjadinya regenerasi vegetasi tersebut.

Tabel 3. Indeks Nilai Penting (INP) Tumbuhan Pakan Orangutan Strata Pancang

\begin{tabular}{lllll}
\hline No & \multicolumn{1}{c}{ Jenis } & $\begin{array}{l}\text { KR } \\
(\mathbf{\%})\end{array}$ & $\begin{array}{l}\text { FR } \\
(\mathbf{\%})\end{array}$ & $\begin{array}{l}\text { INP } \\
(\mathbf{\%})\end{array}$ \\
\hline 1 & Asam Limau Hantu (CitrusBenn.) & 7,40 & 6,06 & 13,4 \\
2 & Bau Langit (Cyathocalix sumatranus) & 17,7 & 15,1 & 32,9 \\
3 & Bintangur Inai (Pternandra caerukescens Jack.) & 4,44 & 6,06 & 10,5 \\
4 & Cempedak (Artocarpus integer) & 14,8 & 16,6 & 31,4 \\
5 & Damli (Streblus elongatus) & 11,8 & 16,6 & 28,5 \\
6 & Jambu Gunung (Psidium sp1.) & 0,74 & 1,51 & 2,25
\end{tabular}




\begin{tabular}{lllll}
7 & Jambu Kepal (Psidium sp2.) & 0,74 & 1,51 & 2,25 \\
8 & Kandis (Garcinia sp.) & 0,74 & 1,51 & 2,25 \\
9 & Kayu Arang (Diospyros sumatrana) & 12,5 & 7,57 & 20,1 \\
10 & Kayu Karet (Elateriospermumtapos) & 14,8 & 12,1 & 26,9 \\
11 & Pala Hutan (Knema furfuraceae) & 1,48 & 3,03 & 4,51 \\
12 & Pakam (Pometia pinnata) & 0,74 & 1,51 & 2,25 \\
13 & Pepening (Shorea multiflora) & 5,92 & 4,54 & 10,4 \\
14 & Tampu Tapak Gajah (Macaranga tribolata) & 0,74 & 1,51 & 2,25 \\
15 & Terap (Artocarpus elasticus) & 5,18 & 4,54 & 9,73 \\
\hline & Jumlah & $\mathbf{1 0 0}$ & $\mathbf{1 0 0}$ & $\mathbf{2 0 0}$ \\
\hline
\end{tabular}

Pada strata pertumbuhan pancang terdapat 15 jenis tumbuhan yang berpotensi dapat digunakan sebagai pakan orang utan sumatera di Stasiun Penelitian Soraya KEL. Jenis-jenis strata pancang yang dominan juga ada 2 jenis tumbuhan pakan orangutan sumatera yang memiliki indeks nilai penting yang tinggi yaitu jenis tumbuhan bau langit (Cyathocalix sumatranus) dengan nilai 32,9\% dan cempedak (Artocarpus integer) dengan nilai 31,4\%. Jenis tumbuhan pakan ini mendominasi pada strata pancang yang terdapat dalam 14 petak contoh pengamatan. Penelitan serupa yang dilakukan oleh Muhammad (2019) di APL Hutan Batang Toru Sumatera Utara ditemukannya 4 jenis tumbuhan pakan pada strata pancang yang dapat dimakan orangutan sedangkan pada Stasiun Penelitian Soraya ditemukannya 15 tumbuhan pakan orangutan sumatera.

Tabel 4. Indeks Nilai Penting (INP) Tumbuhan Pakan Orangutan Strata Semai

\begin{tabular}{llccc}
\hline No & \multicolumn{1}{c}{ Jenis } & $\begin{array}{l}\text { KR } \\
(\boldsymbol{\%})\end{array}$ & $\begin{array}{c}\text { FR } \\
(\boldsymbol{\%})\end{array}$ & $\begin{array}{c}\text { INP } \\
(\boldsymbol{\%})\end{array}$ \\
\hline 1 & Asam Limau Hantu (CitrusBenn.) & 4,08 & 8,51 & 12,5 \\
2 & Berhul (Mangifera foetida) & 1,02 & 2,12 & 3,14 \\
3 & Bintangur Inai (Pternandra caerukescens Jack.) & 23,4 & 19,1 & 42,6 \\
4 & Cempedak (Artocarpus integer) & 28,5 & 19,1 & 47,7 \\
5 & Damli (Streblus elongatus) & 2,04 & 4,25 & 6,29 \\
6 & Durian (Durio oxleyantus) & 1,02 & 2,12 & 3,14 \\
7 & Jambu Gunung (Psidium sp1.) & 14,2 & 19,1 & 33,4 \\
8 & Jambu Kepal (Psidium sp2.) & 2,04 & 2,12 & 4,16 \\
9 & Kayu Karet (Elateriospermum tapos) & 12,2 & 10,6 & 22,8 \\
10 & Pepening (Shorea multiflora) & 11,2 & 12,7 & 23,9 \\
\hline & Jumlah & $\mathbf{1 0 0}$ & $\mathbf{1 0 0}$ & $\mathbf{2 0 0}$ \\
\hline
\end{tabular}

Tumbuhan strata pertumbuhan semai di Stasiun Penelitian Soraya KEL terdapat 10 jenis tumbuhan yang berpotensi digunakan sebagai pakan orangutan sumatera. Dua jenis tumbuhan yang berpotensi sebagai pakan orangutan sumatera yang memiliki indeks nilai penting yang tinggi yaitu jenis cempedak (Artocarpus integer) dengan nilai 47,7\% dan jenis bintangur inai (Pternandra caerukescens Jack.) dengan nilai 42,6\%. Potensi jenis tumbuhan pakan ini mendominasi pada strata semai yang terdapat dalam 14 petak contoh pengamatan. Penelitian Muhammad (2019) hanya terdapat 1 jenis tumbuhan strata semai.

Data perhitungan dan pengumpulan vegetasi tumbuhan pakan orangutan sumatera berdasarkan strata pertumbuhan tegakan perlu dideskripsikan agar diketahui kondisi komunitas tumbuhan. Tumbuhan yang dominan memberikan ciri utama terhadap fisiognomi 
suatu komunitas hutan (Indriyanto, 2006). Perbandingan nilai INP jenis tumbuhan pakan pada setiap strata pertumbuhan menunjukkan bahwa jenis tersebut lebih adaptif terhadap kondisi lingkungan, dimana jenis ini mampu menyesuaikan diri dengan lingkungan tempat hidupnya. Sesuai dengan pernyataan Destaranti et al. (2017) menyatakan bahwa Nilai INP yang tinggi menunjukkan bahwa suatu tumbuhan mempunyai daya adaptasi, daya kompetisi, dan kemampuan reproduksi yang lebih baik dibandingkan dengan tumbuhan lain dalam suatu areal tertentu.

Keempat strata pertumbuhan dari indeks nilai penting yang dominan diantaranya menunjukkan tidak adanya perbedaan yang sangat jauh pada tiap strata pertumbuhan. Tumbuhan pakan orangutan yang dominan dengan indeks nilai penting tertinggi yang terdapat pada setiap strata memiliki peran penting dalam menjaga kestabilan ekosistem di sekitarnya dan memiliki peran penting dalam menjaga ketersediaan pohon pakan bagi orangutan sumatera. Keberadaan tumbuhan pakan pada petak contoh pengamatan di lapangan ini dapat diestmasikan bahwa akan ada kemungkinan orangutan sumatera akan mencari makanan dan membuat sarang pada petak contoh tersebut.

\section{Indeks Keanekaragaman Tumbuhan Pakan Orangutan Sumatera}

Indeks keanekaragaman tumbuhan pakan orangutan sumatera berdasarkan strata pertumbuhan tegakan pada Tabel 5.

Tabel 5. Indeks Keanekaragaman berdasarkan Strata Pertumbuhan

\begin{tabular}{llrc}
\hline No & Strata Pertumbuhan & $\mathrm{H}^{\prime}$ & Besarnya H' \\
\hline 1 & Semai & 1,86 & Sedang \\
2 & Pancang & 2,38 & Sedang \\
3 & Tiang & 3,35 & Tinggi \\
4 & Pohon & 2,62 & Sedang \\
\hline
\end{tabular}

Sumber: Besarnya H’ Facrul 2007

Indeks keanekaragaman tumbuhan pakan orangutan sumatera pada strata semai diperoleh 1,86. Nilai ini menunjukkan bahwa keanekaragaman tumbuhan pakan adalah sedang. Indeks keanekaragaman tumbuhan pakan orangutan sumatera pada strata pancang diperoleh 2,38 menunjukkan bahwa keanekaragaman tumbuhan pakan adalah sedang. Indeks keanekaragaman tumbuhan pakan orangutan sumatera pada strata tiang diperoleh 3,35 menunjukkan bahwa keanekaragaman tumbuhan pakan adalah melimpah tinggi. Indeks keanekaragaman tumbuhan pakan orangutan sumatera strata pohon diperoleh 2,62 menunjukkan bahwa kanekaragaman tumbuhan pakan adalah sedang. Dapat dilihat bahwa indeks keanekaragaman tumbuhan pakan orangutan sumatera tertinggi terdapat pada strata tiang dan indeks keanekaragaman tumbuhan pakan orangutan terendah terdapat pada strata semai. Menurut Sayaktiningsih dan Ma'ruf (2017), indeks keanekaragaman jenis pada tingkat semai lebih rendah dibandingkan tingkat pertumbuhan pancang dan pohon.

Dari hasil perhitungan indeks keanekaragaman jenis tumbuhan pakan orangutan sumatera berkisar 1-3 maka keanekaragaman jenis pada lokasi penelitian ini cukup baik dan 
stabil yang dipengaruhi oleh kondisi lingkungan yang berperan baik dalam mendukung setiap jenis tumbuhan untuk tumbuh dan berkembang sehingga orangutan tetap dapat memenuhi kebutuhan akan pakan. Semakin tinggi keanekaragaman jenis yang dapat dimanfaatkan satwa sebagai sumber pakan, maka keberadaan satwa akan mudah ditemukan. Walaupun kawasan ini pernah mengalami gangguan, akan tetapi saat ini kondisi kawasannya sudah terbilang cukup baik dan memiliki keanekaragaman yang tinggi (Iqbar, 2015)

\section{KESIMPULAN}

INP tertinggi tumbuhan pakan orangutan berdasarkan strata semai yaitu Artocarpus integer (47,7\%), strata pancang yaitu Cyathocalix sumatranus (32,9\%), strata tiang yaitu Streblus elongatus $(46,5 \%)$ dan strata pohon yaitu Dipterocarpus grandiflorus $(57,7 \%)$. Indeks keanekaragaman tumbuhan pakan orangutan sumatera berdasarkan strata pohon sebesar 2,62 (sedang), strata tiang sebesar 3,35 (tinggi), strata pancang sebesar 2,38 (sedang) dan strata semai sebesar 1,86 (sedang).

\section{DAFTAR PUSTAKA}

Acrenaz M, LA, I, and Elehan, H. 2006. Seed spiting and seed swalloing by wild orangutans in Sabah, Malaysia. J Trop Biol Cons Biol. 17:267-272.

Destaranti N, Sulistyanti, Yani E. 2017. Struktur dan vegetasi tumbuhan bawah dan tegakan pinus di RPH Kalirajut dan RPH Baturaden Banyumas. Script Biol. 4(3): 155-160

Fachrul, M., 2007. Metode Sampling Biokelogi. Bumi Aksara. Indonesia.

Indriyanto. (2006). Ekologi Hutan. PT Bumi Aksara. Jakarta.

Iqbar. 2015. Keanekaragaman Tumbuhan Berhabitus Pohon di Stasiun Penelitian Soraya Ekosistem Leuser. Universitas Syiah Kuala, Banda Aceh.

IUCN Red List The Internasional Union for Conservation of Nature Red List of Thereatenede Spesies. 2014.

Kuswanda, W. (2014). Tingkat Perburuan, Pengetahuan Masyarakat dan Kebijakan Perlindungan Trenggiling (Manis javanica) di sekitar Hutan Konservasi. Jurnal Politik dan Kebijakan, 11(2).

Muhammad I. R. 2019. Keanekaragaman Tumbuhan Pakan Orangutan Tapanuli (Pongo tapanuliensis) di Areal Penggunaan Lain (APL) Sekitar Kawasan Hutan Batang Toru Sumatera Utara

Sayaktiningsih T dan Ma'ruf A. 2017. Karakteristik Vegetasi Habitat Orangutan (Pongo pygmaneus morio) Di Hutan Tepi Sungai Menamang, Kalimantan Timur. Jurnal Wasian Vol 4. 17-26. Balikpapan. Balai Penelitian Teknologi Konservasi Sumberdaya Alam. 